\title{
Delta-radiomics and response to neoadjuvant treatment in locally advanced gastric cancer-a multicenter study of GIRCG (Italian Research Group for Gastric Cancer)
}

\author{
Maria Antonietta Mazzei ${ }^{1} \wedge$, Letizia Di Giacomo ${ }^{1}$, Giulio Bagnacci ${ }^{1 \wedge}$, Valerio Nardone ${ }^{2} \wedge$, \\ Francesco Gentili $^{3 \wedge}$, Gabriele Lucii ${ }^{1}$, Paolo Tini ${ }^{4} \wedge$, Daniele Marrelli ${ }^{5} \wedge$, Paolo Morgagni ${ }^{6} \wedge$, Gianni Mura ${ }^{7}$, \\ Gian Luca Baiocchi ${ }^{8}$, Frida Pittiani ${ }^{9}$, Luca Volterrani ${ }^{1} \wedge$, Franco Roviello ${ }^{5}$ \\ ${ }^{1}$ Department of Medical, Surgical and Neuro Sciences, University of Siena and Department of Radiological Sciences, Unit of Diagnostic Imaging, \\ Azienda Ospedaliera Universitaria Senese, Siena, Italy; ${ }^{2}$ Unit of Radiation Therapy, Ospedale del Mare, Naples, Italy; ${ }^{3}$ Section of Radiology, Unit \\ of Surgical Sciences, University of Parma, Parma, Italy; ${ }^{4}$ Unit of Radiation Oncology, Azienda Ospedaliera Universitaria Senese, Siena, Italy; \\ ${ }^{5}$ Department of Medical, Surgical and Neuro Sciences, Unit of Surgical Oncology, University of Siena, Azienda Ospedaliera Universitaria Senese, \\ Siena, Italy; ${ }^{6}$ Department of General Surgery, Morgagni-Pierantoni Hospital, Forlì, Italy; ${ }^{7}$ Department of Surgery, San Donato Hospital, Arezzo, \\ Italy; ${ }^{8}$ Department of Clinical and Experimental Studies, Surgical Clinic, University of Brescia, Brescia, Italy; ${ }^{9}$ Department of Radiology, ASST \\ Spedali Civili Brescia, Brescia, Italy
}

Correspondence to: Giulio Bagnacci. Department of Medical, Surgical and Neuro Sciences, University of Siena and Department of Radiological Sciences, Unit of Diagnostic Imaging, Azienda Ospedaliera Universitaria Senese, Viale Bracci, 16. Siena 53100, Italy. Email: giuliobagnacci@gmail.com.

Background: To predict response to neoadjuvant chemotherapy (NAC) of gastric cancer (GC), prior to surgery, would be pivotal to customize patient treatment. The aim of this study is to investigate the reliability of computed tomography (CT) texture analysis (TA) in predicting the histo-pathological response to NAC in patients with resectable locally advanced gastric cancer (AGC).

Methods: Seventy (40 male, mean age 63.3 years) patients with resectable locally AGC, treated with NAC and radical surgery, were included in this retrospective study from 5 centers of the Italian Research Group for Gastric Cancer (GIRCG). Population was divided into two groups: 29 patients from one center (internal cohort for model development and internal validation) and 41 from other four centers (external cohort for independent external validation). Gross tumor volume (GTV) was segmented on each pre- and postNAC multidetector CT (MDCT) image by using a dedicated software (RayStation), and 14 TA parameters were then extrapolated. Correlation between TA parameters and complete pathological response (tumor regression grade, TRG1), was initially investigated for the internal cohort. The univariate significant variables were tested on the external cohort and multivariate logistic analysis was performed.

Results: In multivariate logistic regression the only significant TA variable was delta gray-level cooccurrence matrix (GLCM) contrast $\left(\mathrm{P}=0.001\right.$, Nagelkerke $\mathrm{R}^{2}: 0.546$ for the internal cohort and $\mathrm{P}=0.014$, Nagelkerke $R^{2}$ : 0.435 for the external cohort). Receiver operating characteristic (ROC) curves, generated from the logistic regression of all the patients, showed an area under the curve (AUC) of 0.763 .

Conclusions: Post-NAC GLCM contrast and dissimilarity and delta GLCM contrast TA parameters seem to be reliable for identifying patients with locally AGC responder to NAC.

Keywords: Stomach neoplasms; neoadjuvant therapy; multidetector computed tomography (MDCT)

^ ORCID: Maria Antonietta Mazzei, 0000-0001-6778-6894; Giulio Bagnacci, 0000-0002-5797-1129; Valerio Nardone, 0000-00027347-0965; Francesco Gentili, 0000-0003-2492-5844; Paolo Tini, 0000-0003-4826-4809; Daniele Marrelli, 0000-0003-2066-1618; Paolo Morgagni, 0000-0002-1564-2415; Gianni Mura, 0000-0002-4521-3101; Gian Luca Baiocchi, 0000-0003-2402-2178. 
Submitted May 27, 2020. Accepted for publication Jan 20, 2021.

doi: 10.21037/qims-20-683

View this article at: http://dx.doi.org/10.21037/qims-20-683

\section{Introduction}

Although the overall incidence of gastric cancer (GC) has progressively decreased during the last decades, it still remains the fourth most common malignancy and the thirdleading cause of cancer-related death $(1,2)$; nevertheless, in Western countries, the disease is often at an advanced stage at the time of diagnosis and in more than two thirds of cases is unresectable or metastatic (3-5). To date surgery remains the only potentially curative modality to treat GC; however, it has been observed that a number of patients with locally advanced gastric cancer (AGC), who received R0 gastrectomy with extended (D2) lymphadenectomy, still develop distant metastases and loco-regional recurrences (6). For this reason, neoadjuvant chemotherapy (NAC) has been introduced successfully in the treatment of locally AGC $(7,8)$ and it is now considered a standard treatment of care in Europe, with its effect in decreasing the tumor size (down-sizing) and the tumor stage (down-staging), increasing the R0 resection rate (9) and improving both overall and progression-free survival (PFS) $(10,11)$. Anyway, a large amount (40-64\%) of patients submitted to NAC do not present response to therapy (12) and critical points are monitoring of response and early identification of responder patients to chemotherapy. Histological tumor regression grade (TRG) after chemotherapy is considered an important prognostic and objective parameter of response evaluation, however it can only be assessed after surgery $(13,14)$. An early detection of non-responder patients is important to not delay curative surgery and to avoid the toxicity induced by chemotherapy which may lead to increased surgical complications $(7,11)$.

Traditional computed tomography (CT) is the imaging modality usually employed for staging and restaging GC patients after NAC, thanks to its high spatial resolution, large availability and low-cost (15); however, to date, there is no gold-standard criteria to objectify response to treatment, since gastric lesion is hardly measurable $(16,17)$ and therefore not correctly evaluated adopting RECIST (18-20).

An emerging tool, which may play an important role in this field, is the texture analysis (TA), which belongs to the field of radiomics. This technique, can be applied to conventional CT images and seems to be able to detect subtle differences in CT values which cannot be recognized by human eyes (21), providing quantitative data on tumor microenvironment by analyzing the distribution and relationship of pixel or voxel gray levels in the image (22-24).

The aim of this study was to test the value of TA, applied to CT images, in predicting histological response of locally AGC to NAC.

\section{Methods}

\section{Patient selection}

This retrospective study was approved by the institutional review boards of our hospitals and written informed consent for medical photographs was obtained from all subjects. Abdominal CT examinations of 70 patients were retrospectively reviewed from a cohort of 121 patients treated with NAC followed by gastrectomy in 5 Italian Research Group for Gastric Cancer (GIRCG) centers, between June 2010 and February 2019.

The inclusion criteria were the following: (I) biopsyproven, locally AGC without distant metastases (i.e., clinical parameters $\mathrm{T} \geq 3$ and/or $\mathrm{N}+, \mathrm{M} 0$ ); (II) NAC before surgery and radical resection; (III) an interval time between restaging CT and surgery $\leq 30$ days; (IV) the availability of histopathological response (TRG) according to Becker et al. (25). Fifty-one patients were excluded because of an interval between restaging CT and surgery longer than 30 days $(\mathrm{n}=3)$, presence of metastatic disease at restaging CT $(n=4)$, neoplastic involvement of the esophagus $(n=2)$, clinical complications during chemotherapy requiring urgent surgery $(n=3)$, inappropriate CT methodology or technical parameters $(n=6)$, use of a CT scanner with a number of slice lower than $64(n=25)$, impossibility to import CT images on software for image segmentation $(\mathrm{n}=4)$, unavailability of CT post-NAC $(\mathrm{n}=1)$, other technical problems such as corrupted digital supports $(n=3)$. Finally, 70 patients [40 male; 30 female; mean age 62.9; standard deviation (SD) 10.5 years] were enrolled in this study. The population was divided in two groups as follows: 29 patients enrolled from Siena University Hospital were considered as internal cohort (group 1) and 41 from the other GIRCG centers (Forlì Hospital, Montevarchi Hospital, Brescia Hospital and Verona Hospital) as external cohort (group 2) 
Table 1 Internal and external cohorts of patients

\begin{tabular}{lcc}
\hline Population & Internal patients & External patients \\
\hline Total patients & 29 & 41 \\
Gender & $17 \mathrm{M}, 12 \mathrm{~F}$ & $\mathrm{M}, 17 \mathrm{~F}$ \\
Median age & $63.3 \pm 11.5$ & $62.7 \pm 9.8$ \\
Responders (Becker 1) & 3 & 8 \\
Non responders (Becker 2-3) & 26 & 33 \\
Lauren classification & & 21 \\
Intestinal & 14 & 17 \\
Diffuse & 12 & 2 \\
Mixed & 2 & 1 \\
Non classified & 1 & \\
\hline
\end{tabular}

M, male; F, female.

Table 2 Different chemotherapy regimens and number of patients with percentage in relation to single cohort population

\begin{tabular}{lcc}
\hline Chemotherapy regimen & Internal cohort & External cohort \\
\hline ECF (epirubicin, cisplatin and 5-fluorouracil) & $5(17.2 \%)$ & $6(14.7 \%)$ \\
DOX (docetaxel, oxaliplatin and capecitabine) & $15(51.7 \%)$ & $23(56.1 \%)$ \\
EOX (capecitabine, oxaliplatin and ED epirubicin) & $3(10.3 \%)$ & $4(9.8 \%)$ \\
DCF (docetaxel, cisplatin and 5-fluorouracil) & $1(3.5 \%)$ & $1(2.4 \%)$ \\
2ECF + 4DCF & $1(3.5 \%)$ & - \\
CDDP (cisplatin + capecitabine) & $3(10.3 \%)$ & $5(12.2 \%)$ \\
FOLFOX (folic acid, fluorouracil and oxaliplatin) & - & $1(2.4 \%)$ \\
1DOX + 3DOF (docetaxel, oxaliplatin and fluorouracil) & $1(3.5 \%)$ & - \\
EOF (epirubicin, oxaliplatin and 5-fluorouracil) &
\end{tabular}

for independent external validation (Table 1). The different chemotherapy regimens used are reported in Table 2.

\section{CT and image analyses}

All 70 patients underwent CT scans (CTs) within 1 week before the beginning of NAC and within a maximum of 30 days (mean $20 \pm 6.4$ days) after completion of NAC before surgery. All patients who underwent the CTs had fasted for 8 hours. Stomach distention was obtained with air or with water; in particular, air distention was obtained by administering two pouches of effervescent granules per os, together with $10 \mathrm{~mL}$ of water, 3 minutes before the scan, while water distention was obtained by asking patients to drink 3 or 4 glasses of water $(125 \mathrm{~mL})$ immediately before the exam. All patients also received $1 \mathrm{mg}$ of glucagon (GlucaGen, Novo Nordisk) or $20 \mathrm{mg}$ of hyoscine butylbromide (Buscopan, Pharmamedix) intravenously, in order to induce gastric hypotonia. The same inflation technique was used both in staging and restaging CTs for each patient, in order to reduce the bias deriving from the different degree of gastric distention. CTs were acquired with a spiral technique by using a 64-detector row configuration (VCT, General Electric Healthcare, Milwaukee, USA in 29 cases and LightSpeed Plus, GE Healthcare, Milwaukee, USA in 41 cases). The following protocol was used: after a scout view, an unenhanced upper abdominal CT scan was acquired from the diaphragmatic domes to $2 \mathrm{~cm}$ below the lower 
Table 3 CT technical parameters, with slice thickness referred to the late arterial phase

\begin{tabular}{ll}
\hline CT technical parameters & Details \\
\hline Slice thickness $(\mathrm{mm})$ & $1.25 \mathrm{~mm}$ for 29 patients and $2.00 \mathrm{~mm}$ for 41 patients \\
Beam pitch & $0.9 / 1.3$ \\
Reconstruction interval $(\mathrm{IR})$ & At least half of the effective slice thickness \\
Tube voltage $(\mathrm{kVp})$ & $120-140$ \\
Reference $\mathrm{mAs}$ & $200 / 250-500 / 600$ \\
\hline
\end{tabular}

$\mathrm{CT}$, computed tomography.

margin of the gastric body to confirm the distention of the stomach. Contrast-enhanced CTs were performed in the late arterial phase (start delay 45-50 s) in the upper abdomen and in the portal venous phase (start delay 70-80 s) from pelvic brim to thoracic inlet, after an intravenous injection of $2 \mathrm{~mL} / \mathrm{kg}$ of nonionic contrast material (iodine concentration $\geq 350 \mathrm{mg} / \mathrm{mL}$ ), followed by $40 \mathrm{~mL}$ of saline solution, using a semiautomated power injector (3.5-4.0 $\mathrm{mL} / \mathrm{s}$ flow rate) with an $18 / 20$-gauge needle in the antecubital vein. A delayed CT scan after 5 minutes was used to characterize uncertain liver lesions. An automatic current modulation tube was used to minimize radiation exposure. Images reconstruction was performed by using a standard reconstruction algorithm. CT technical parameters are reported in Table 3.

Images of post-contrast late arterial phase of both preand post-NAC CTs were retrieved from a picture archiving and communication system (PACS). Gross tumor volume (GTV) was manually contoured on each slice, in the axial plane, along the outer edge of gastric lesion, by using a dedicated software (RayStation), trying to exclude from segmentation vessels and gastric contents (Figure 1). Each volume was interpreted and segmented in consensus by two radiologists with 5- and 16-year experience in abdominal CT, respectively, blinded to the clinicopathological information such as TNM stage, degree of tumor differentiation and histopathological response according to Becker. The impact of variations on contouring was analyzed performing two delineation on a small sample set of patients (namely 20), and the TA parameters were tested for reliability with intraclass coefficient correlation (ICC) method both in the images before and after NAC. The delta TA parameters, meaning the difference between the same TA parameter extrapolated from images before and after NAC, for each TA parameter, were tested for reliability with ICC. Only reliable TA parameters (ICC $>0.70$, single measure) were then selected.

All the analyzes for this work have been accomplished with LifeX Software ${ }^{\odot}$ (25). TA parameters included features of gray-level co-occurrence matrix (GLCM), compacity, sphericity and indices from the gray-level histogram, for a total of 14 parameters.

Parameters were extracted by using the following constants: spatial resampling (X: $2 \mathrm{~mm}, \mathrm{Y:} 2 \mathrm{~mm}, \mathrm{Z}: 2 \mathrm{~mm}$ ), intensity discretization (number of gray levels: 64, size of bins: 10), intensity rescaling (absolute, min bound: $-1,000 \mathrm{HU}$, max bound: 3,000 HU).

\section{Pathological evaluation}

Post-operative histopathological findings were evaluated by expert gastrointestinal pathologists. At the macroscopic examination, tumors were classified according to the criteria proposed by Borrmann et al. (26).

At least five tissue blocks from the tumor site were taken if tumor was grossly visible; if the viable tumor was not grossly evident, the whole suspicious area was embedded with step sectioning at $5 \mathrm{~mm}$ (13).

Lymph nodes samples were distinguished in stations according to the Japanese Research Society for Gastric Cancer (JRSGC) classification (27).

TRG was evaluated according to the Becker classification as percentage of residual neoplasia in the macroscopically evaluated tumor bed. TRG1 was defined as complete or subtotal tumor regression with $<10 \%$ residual tumor cells; TGR2 as partial tumor regression with $10-50 \%$ residual tumor cells; and TRG3 as minimal or absent regression with $>50 \%$ residual tumor cells with or without signs of treatment effects $(13,25)$. We considered patients with grade 1 as responders and patients with grade 2 or 3 as non-responders in this study, as there are several evidences showing that patients with complete or subtotal tumoral 

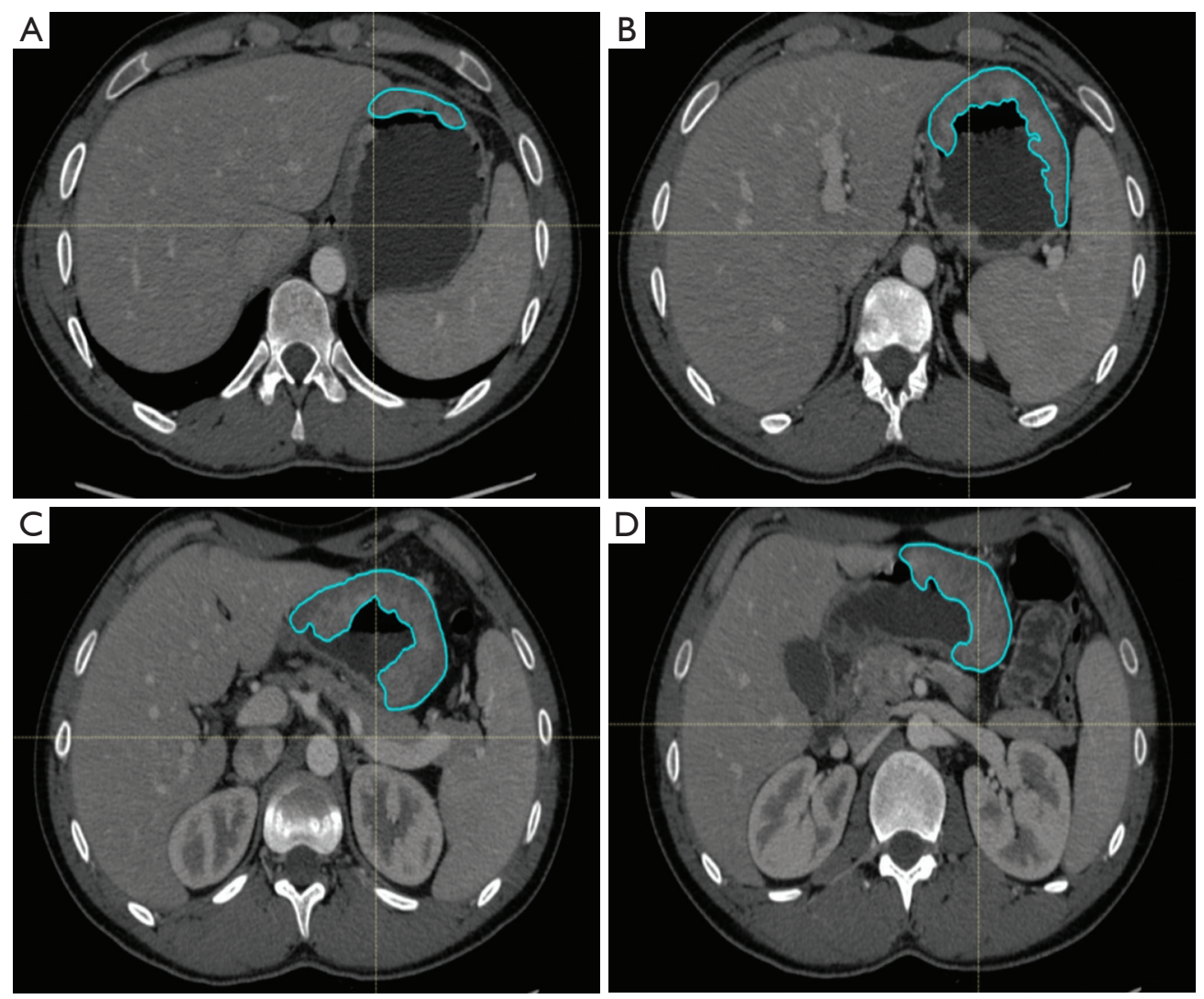

Figure 1 Example of gastric cancer contouring before neoadjuvant chemotherapy. GTV was manually drawn through a ROI on each CT slice (A,B,C,D) and not only where neoplasm was more evident. GTV, gross tumor volume; ROI, region of interest.

regression (TRG $1 \mathrm{a}$ and $1 \mathrm{~b}$ respectively) have a better prognosis compared to those with partial or minimal tumor regression (TRG 2 and 3 respectively) $(28,29)$.

Cancer staging and residual tumor in surgical margins (R) were classified according to American Joint Committee on Cancer (AJCC) 8th edition (30).

\section{Statistical analysis}

The reliable TA parameters (ICC $>0.70$, single measure) were then correlated with the development of complete pathological response (TRG1), for the internal cohort of patients, by performing a univariate analysis (univariate logistic regression, with Bonferroni correction for the number of variables). We analyzed the correlation between the significant TA parameters and, if a correlation larger than 0.80 was observed (Pearson correlation), then the variable with the lowest univariable correlation with the endpoint was omitted, to avoid the risk of overfitting the model and of multicollinearity (31) in the multivariate analysis (binary logistic regression), with a method similar to previous works (32).

Logistic regression analysis was optimized by using the internal cohort of patient, and the outcome of the testing data was then predicted within the optimized model also in the external cohort. The ROC curve was then extrapolated by the binary logistic regression of the two datasets (internal and external cohort). In multivariate analysis also tumor volume change before and after NAC was correlated with TRG1.

All the statistical analysis was conducted with SPSS software 23.0 and a $\mathrm{P}$ value $<0.05$ was considered statistically significant.

\section{Results}

\section{Patient characteristics}

Among the 70 patients enrolled, tumors were in the fundus 
Table 4 Texture features concerning pre- and post-neoadjuvant chemotherapy (NAC) and relative intraclass coefficient correlation (ICC) between the two readers

\begin{tabular}{|c|c|c|}
\hline TA parameters & Pre-NAC & Post-NAC \\
\hline Volume.ml & $0.986^{*}$ & $0.977^{\star}$ \\
\hline Volume.vx & $0.982^{*}$ & $0.980^{*}$ \\
\hline Skewness & 0.160 & 0.201 \\
\hline Kurtosis & 0.206 & 0.244 \\
\hline Entropy & $0.753^{*}$ & $0.873^{*}$ \\
\hline Energy & $0.792^{*}$ & $0.925^{\star}$ \\
\hline Sphericity & 0.641 & $0.719^{*}$ \\
\hline Compacity & $0.949^{*}$ & $0.938^{*}$ \\
\hline GLCM.homogeneity & $0.793^{*}$ & $0.869^{*}$ \\
\hline GLCM.energy & $0.897^{\star}$ & $0.966^{*}$ \\
\hline GLCM.contrast & $0.968^{*}$ & $0.886^{*}$ \\
\hline GLCM.correlation & $0.989^{*}$ & $0.977^{\star}$ \\
\hline GLCM.entropy & $0.766^{\star}$ & $0.867^{*}$ \\
\hline GLCM.dissimilarity & $0.951^{*}$ & $0.868^{*}$ \\
\hline
\end{tabular}

*, significant reproducible values. TA, texture analysis; GLCM, gray-level co-occurrence matrix.

$(\mathrm{n}=5)$, body $(\mathrm{n}=23)$, antrum $(\mathrm{n}=28)$ cardia and body $(\mathrm{n}=8)$ or antrum and body $(n=6)$ of the stomach. Histopathological analysis revealed the following GC histotypes, according to Lauren (33): 14 intestinal, 12 diffuse, 2 mixed and 1 non classified from the internal cohort and 21 intestinal, 17 diffuse, 2 mixed, and 1 non classified from the external cohort. Three out of 29 patients from the internal cohort and 8 out of 41 patients from the external cohort were classified as TRG1 according to Becker et al. (11 TRG1 in total). Six out of these 11 cases were intestinal, 4 diffuse and 1 non-classified GC.

\section{TA and histopathologic correlation}

The reliability analysis of TA parameters, performed with ICC, showed that 11 out of 14 parameters for pre-NAC images and 12 out of 14 TA parameters for the post-NAC images were significantly reproducible among the two different contourings (ICC $>0.70$, single measure) and were included in the further feature selection process (Table 4). Within the internal cohort, the following TA parameters were significantly correlated with the endpoint (TRG1):
post-GLCM contrast $(\mathrm{P}=0.017)$, post-GLCM dissimilarity $(\mathrm{P}=0.027)$, delta entropy $(\mathrm{P}=0.002)$, delta GLCM contrast $(\mathrm{P}<0.001)$, delta $\mathrm{GLCM}$ entropy $(\mathrm{P}=0.006)$ and delta GLCM dissimilarity $(\mathrm{P}<0.001)$ (Figure 2). Post-GLCM contrast and dissimilarity, as well as delta entropy and delta GLCM entropy were excluded because of a correlation greater than 0.8 each other; therefore, delta GLCM contrast and delta GLCM dissimilarity were considered for multivariate analysis and only delta GLCM contrast proved to be significant ( $\mathrm{P}=0.001$, Nagelkerke $\mathrm{R}^{2}$ : 0.546). All the significant variables on univariate analysis of the internal cohort, except delta GLCM entropy, proved to be significant in the external cohort (Figure 3). Multivariate logistic regression performed on the external dataset showed that delta GLCM contrast was the only significant parameter $\left(\mathrm{P}=0.014\right.$, Nagelkerke $\left.\mathrm{R}^{2}: 0.435\right)$ in the external cohort too.

ROC curve was generated from the logistic regression of all the cohort of patients, showed an AUC of 0.763 (standard error: $0.098, \mathrm{P}=0.006$, lower bound: 0.571 , upper bound: 0.954) (Figure 4).

Tumor volume change was not significantly correlated with TRG1 $(\mathrm{P}=0.07)$.

\section{Discussion}

The overall survival (OS) in AGC is still very poor, also after radical surgery and extended nodal dissection (34). For this reason, NAC has been successfully introduced in the treatment of locally AGC, in order to decrease tumor size and downstage the disease, increasing the R0 resection rate and improving both PFS and OS versus surgery alone $(10,11)$. However, lack of response to NAC may delay curative surgery, and chemotherapy-induced toxicity may lead to increase surgical complications (12). Therefore, it would be of crucial importance to find a reliable way to distinguish responder from non-responder patients, so that non-responders may directly undergo to surgery after the early assessment through imaging during NAC.

Some works successfully investigated the feasibility of CT in predicting histopathological response of GC after NAC, by measuring tumor volume and maximum diameter reduction rate $(35,36)$, despite visual assessment may be affected by a large inter and intraobserver variability and reduction of tumor volume is not always correlated with response to therapy. Also advanced imaging modalities, such as dual energy CT (DECT) and CT perfusion were investigated in predicting histopathological response of 

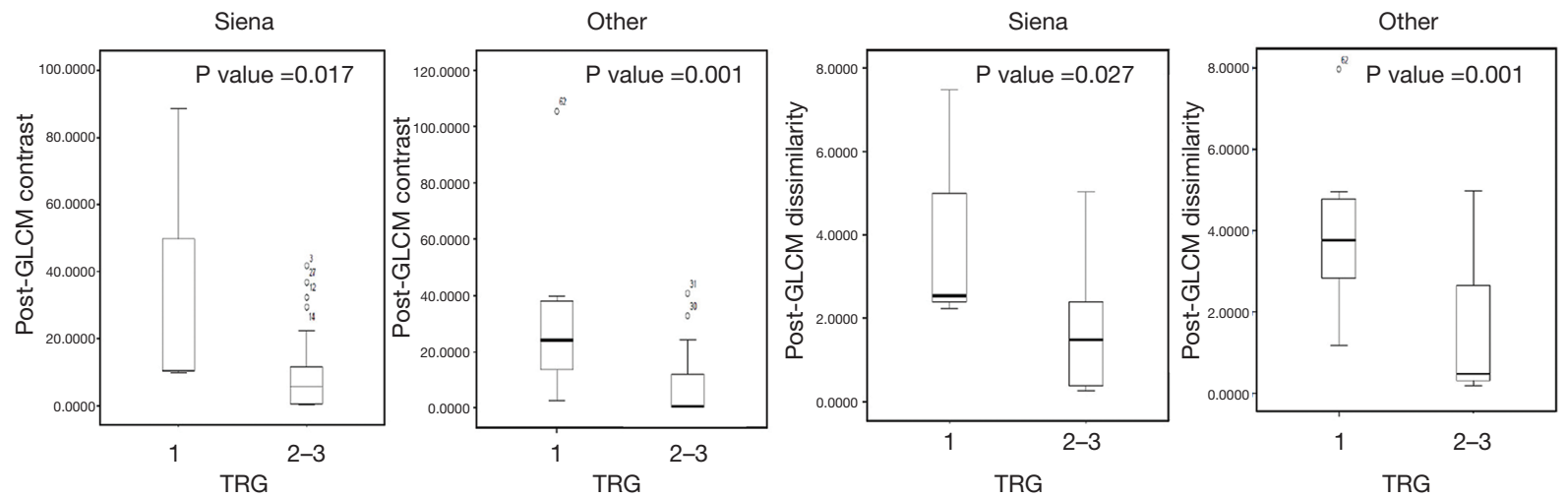

Figure 2 Boxplots showing the two post-neoadjuvant chemotherapy texture features significantly correlated to histopathologic outcome: GLCM contrast and GLCM dissimilarity. GLCM, gray-level co-occurrence matrix; TRG, tumor regression grade.
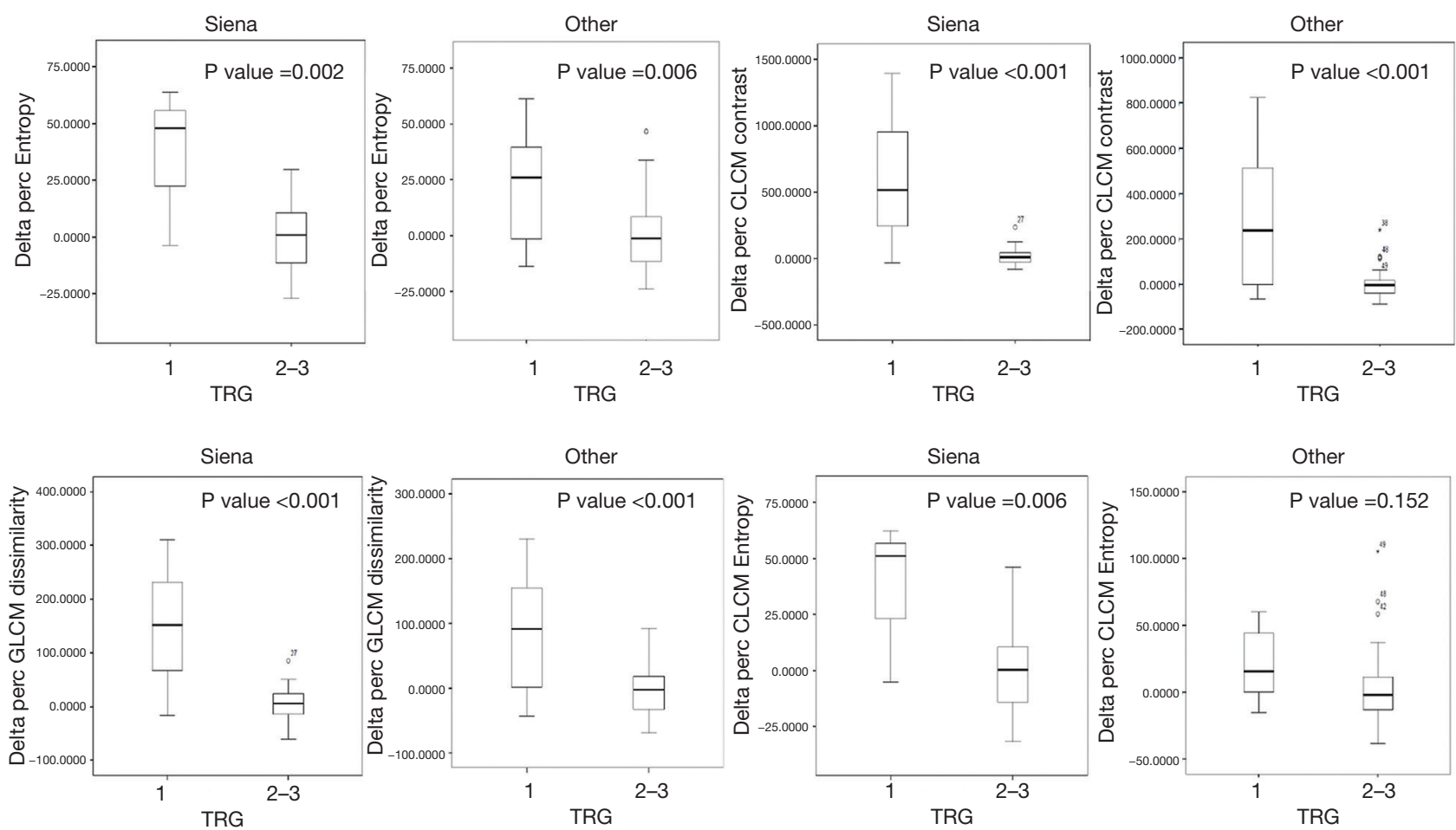

Figure 3 Boxplots showing the four delta texture features (relative percentage variations) significantly correlated with the histopathologic outcome: delta entropy, delta GLCM contrast, delta GLCM dissimilarity and delta GLCM entropy, the last significant only on the first group (internal cohort of patients). GLCM, gray-level co-occurrence matrix; TRG, tumor regression grade.

AGC after NAC (37-39), however, CT perfusion is still affected by some important issues $(40,41)$, in particular regarding the reproducibility and the possibility to compare its results with different proprietary softwares $(42,43)$ whereas DECT is affected by the fact that not all neoplastic lesions are hypervascular and that the reduction of vascularization after chemotherapy is not always strictly related to tumor response (44-46).

In this sense TA, analyzing the distribution of pixels or voxels gray level in digital images, makes possible to extrapolate mathematical parameters (texture features) which reflect the underlying structure of the objects 


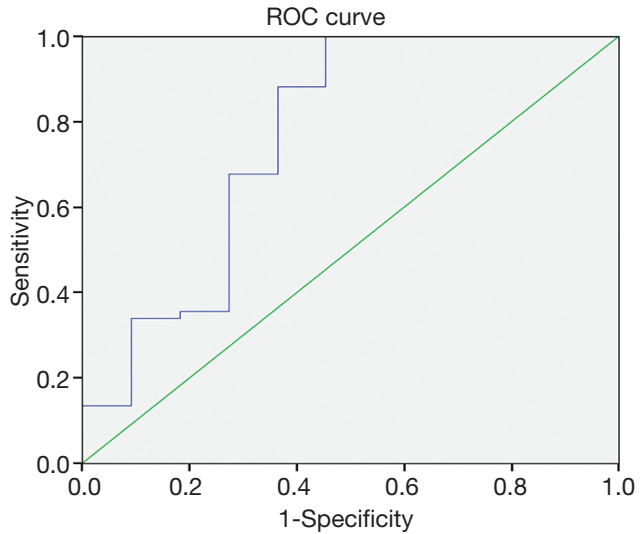

Figure 4 ROC curve was generated from the binary logistic regression using only delta GLCM contrast as predictor variable. AUC resulted to be 0.763 (standard error: 0.098, $\mathrm{P}=0.006$, lower bound: 0.571, upper bound: 0.954). ROC, receiver operating characteristic; GLCM, gray-level co-occurrence matrix.

showed in the image (21-23). The use of this technique in oncology could make images interpretation more objective, as it provides quantitative information concerning tumor heterogeneity, which are invisible to human eyes $(22,23)$. This new technique has already been found to be a potential predictive biomarker of response to therapy or survival for several neoplasms such as lung (47), breast (48), kidney (49) and colorectal (50) cancer and also to predict treatment complications (51-55). Few studies have been conducted until now regarding TA application to GC; nevertheless, results have been encouraging. Yoon et al. demonstrated that higher values of contrast and variance and lower values of correlation and angular second moment (ASM) were associated with an increased tumor heterogeneity and better survival in patients with HER2-positive AGC who were treated with trastuzumab (56). Giganti et al. showed that pre-treatment TA can reflect tumor features at a cellular level and provides important information regarding the response rate to NAC (57). Moreover, further studies showed other potential roles of TA such as: differential diagnosis between histological subtypes of GC, evaluation of tumor differentiation degree, Lauren classification and vascular invasion $(58,59)$.

The aim of this study was to assess the reliability of TA applied to CT in predicting histopathologic response to NAC in patients with locally AGC before surgery. No statistically significant correlation was found between any single pre-NAC TA parameter and histologic outcome, neither in the internal cohort, nor in the external one. Otherwise, results concerning both internal and external cohort of patients, showed that two post-NAC TA features (GLCM contrast and dissimilarity) were significantly correlated to the endpoint $(\mathrm{P}=0.017$ and $\mathrm{P}=0.001$ respectively and post GLCM dissimilarity $\mathrm{P}=0.027$ and $\mathrm{P}=0.001$ respectively), being tendentially higher in responder patients. Moreover, values of relative changes of TA features before and after NAC, and in particular delta GLCM contrast, were significantly different between responders and non-responder patients and tended to be higher in the first group; this finding seems to reflect an increase of the histopathologic heterogeneity of neoplastic tissue induced by treatment and confirm our preliminary results (60). According to our study, Rao et al. showed that the relative changes after chemotherapy of TA entropy and uniformity were significant predictors of histopathologic response to chemotherapy in patients with colorectal cancer liver metastases; interestingly, as well as in our case, the authors failed to demonstrate a benefit for pre-NAC TA parameters in predicting response (61).

In our study most results of the internal cohort were confirmed for the external cohort of patients, although CTs were performed with different setting; given that we didn't apply any filter to the images, we may suppose that TA features are not strictly influenced by CT technical parameters.

This study has some limitations. First of all, the number of patients was small, despite multicenter study; moreover, NAC schemes were different, even if similarly distributed in the two cohorts. Second, regarding data collection, in some cases the distention grade of the stomach was significantly different between pre- and post-NAC CTs and this factor may have caused under- or overestimation of GTV, especially when the lesion was very thin. Third, given that the stomach is a cave organ, it was sometimes hard to avoid the inclusion of gastric content or vessels in the contouring, operation that could have altered TA results. However, to our knowledge, this is the first study correlating variations of TA parameters, obtained from CT examinations, with histopathologic response (Becker's score) in patients with resectable AGC. Furthermore, to date, this is the only study in literature on TA in GC with an external validation cohort that allows to reach the target of reproducibility, hard to overcome in most TA studies due to different methodologies and software programs. Moreover, it is one of the few studies where TA was performed on the entire tumor volume instead of the largest two-dimensional 
section. Surely, larger, prospective and multicentric studies, performed with the same standardized software, are needed to confirm our results.

In conclusion, the possible value of TA in the clinical practice of the treatment of GC is still to be clarified. This study suggests that TA is an imaging biomarker which can provide addictive information to conventional CT, since it reflects tumor heterogeneity variations that cannot be captured by human eyes. Post-NAC GLCM contrast and dissimilarity and delta GLCM contrast could potentially be predictive of response to NAC in patients with AGC. If these results would be further confirmed, this new technique may become a reliable tool to identify responder patients in a pre-surgical phase, suggesting stopping NAC and proceed to surgery in case of poor response.

\section{Acknowledgments}

This study has already been partially reported in the Proceedings of XV Congress OIC.8 - Oncologic Imaging Course 2018 and European Congress of Radiology ECR 2019. Funding: None.

\section{Footnote}

Conflicts of Interest: All authors have completed the ICMJE uniform disclosure form (available at http://dx.doi. org/10.21037/qims-20-683). The authors have no conflicts of interest to declare.

Ethical Statement: This retrospective study was approved by the institutional review boards of our hospitals and written informed consent for medical photographs was obtained from all subjects.

Open Access Statement: This is an Open Access article distributed in accordance with the Creative Commons Attribution-NonCommercial-NoDerivs 4.0 International License (CC BY-NC-ND 4.0), which permits the noncommercial replication and distribution of the article with the strict proviso that no changes or edits are made and the original work is properly cited (including links to both the formal publication through the relevant DOI and the license). See: https://creativecommons.org/licenses/by-nc-nd/4.0/.

\section{References}

1. Ferlay J, Soerjomataram I, Dikshit R, Eser S, Mathers
C, Rebelo M, Parkin DM, Forman D, Bray F. Cancer incidence and mortality worldwide: sources, methods and major patterns in GLOBOCAN 2012. Int J Cancer 2015;136:E359-86.

2. Sitarz R, Skierucha M, Mielko J, Offerhaus GJA, Maciejewski R, Polkowski WP. Gastric cancer: epidemiology, prevention, classification, and treatment. Cancer Manag Res 2018;10:239-48.

3. Coccolini F, Montori G, Ceresoli M, Cima S, Valli MC, Nita GE, Heyer A, Catena F, Ansaloni L. Advanced gastric cancer: What we know and what we still have to learn. World J Gastroenterol 2016;22:1139-59.

4. Marrelli D, Polom K, de Manzoni G, Morgagni P, Baiocchi GL, Roviello F. Multimodal treatment of gastric cancer in the west: Where are we going? World J Gastroenterol 2015;21:7954-69.

5. Kuo CY, Chao Y, Li CP. Update on treatment of gastric cancer. J Chin Med Assoc 2014;77:345-53.

6. Swan R, Miner TJ. Current role of surgical therapy in gastric cancer. World J Gastroenterol 2006;12:372-9.

7. Xu AM, Huang L, Liu W, Gao S, Han WX, Wei ZJ. Neoadjuvant chemotherapy followed by surgery versus surgery alone for gastric carcinoma: systematic review and meta-analysis of randomized controlled trials. PLoS One 2014;9:e86941.

8. Chua YJ, Cunningham D. The UK NCRI MAGIC trial of perioperative chemotherapy in resectable gastric cancer: implications for clinical practice. Ann Surg Oncol 2007;14:2687-90.

9. Ychou M, Boige V, Pignon JP, Conroy T, Bouché O, Lebreton G, Ducourtieux M, Bedenne L, Fabre JM, SaintAubert B, Genève J, Lasser P, Rougier P. Perioperative chemotherapy compared with surgery alone for resectable gastroesophageal adenocarcinoma: an FNCLCC and FFCD multicenter phase III trial. J Clin Oncol 2011;29:1715-21.

10. Xu W, Beeharry MK, Liu W, Yan M, Zhu Z. Preoperative Chemotherapy for Gastric Cancer: Personal Interventions and Precision Medicine. Biomed Res Int 2016;2016:3923585.

11. Téoule P, Trojan J, Bechstein W, Woeste G. Impact of Neoadjuvant Chemotherapy on Postoperative Morbidity after Gastrectomy for Gastric Cancer. Dig Surg 2015;32:229-37.

12. Samalin E, Ychou M. Neoadjuvant treatment in upper gastrointestinal adenocarcinomas: new paradigms from old concepts? Curr Opin Oncol 2007;19:384-9.

13. Becker K, Langer R, Reim D, Novotny A, Meyer zum 
Buschenfelde C, Engel J. Significance of histopathological tumor regression after neoadjuvant chemotherapy in gastric adenocarcinomas: a summary of 480 cases. Ann Surg 2011;253:934-9.

14. Langer R, Becker K. Tumor regression grading of gastrointestinal cancers after neoadjuvant therapy. Virchows Arch 2018;472:175-86.

15. Kwee RM, Kwee TC. Role of imaging in predicting response to neoadjuvant chemotherapy in gastric cancer. World J Gastroenterol 2014;20:1650-6.

16. Japanese Gastric Cancer Association. Japanese classification of gastric carcinoma--2nd English edition-response assessment of chemotherapy and radiotherapy for gastric carcinoma: clinical criteria. Gastric Cancer 2001;4:1-8.

17. Liu K, Li G, Fan C, Zhou C, Li J. Adapted Choi response criteria for prediction of clinical outcome in locally advanced gastric cancer patients following preoperative chemotherapy. Acta Radiol 2012;53:127-34.

18. Eisenhauer EA, Therasse P, Bogaerts J, Schwartz LH, Sargent D, Ford R. New response evaluation criteria in solid tumours: revised RECIST guideline (version 1.1). Eur J Cancer 2009;45:228-47.

19. Schwartz LH, Litière $S$, de Vries E, Ford R, Gwyther S, Mandrekar S, Shankar L, Bogaerts J, Chen A, Dancey J, Hayes W, Hodi FS, Hoekstra OS, Huang EP, Lin N, Liu Y, Therasse P, Wolchok JD, Seymour L. RECIST 1.1-Update and clarification: From the RECIST committee. Eur J Cancer 2016;62:132-7.

20. Schwartz LH, Seymour L, Litière S, Ford R, Gwyther S, Mandrekar S, Shankar L, Bogaerts J, Chen A, Dancey J, Hayes W, Hodi FS, Hoekstra OS, Huang EP, Lin N, Liu Y, Therasse P, Wolchok JD, de Vries E. RECIST 1.1 - Standardisation and disease-specific adaptations: Perspectives from the RECIST Working Group. Eur J Cancer 2016;62:138-45.

21. Castellano G, Bonilha L, Li LM, Cendes F. Texture analysis of medical images. Clin Radiol 2004;59:1061-9.

22. Lubner MG, Smith AD, Sandrasegaran K, Sahani DV, Pickhardt PJ. CT Texture Analysis: Definitions, Applications, Biologic Correlates, and Challenges. Radiographics 2017;37:1483-503.

23. Ganeshan B, Miles KA. Quantifying tumour heterogeneity with CT. Cancer Imaging 2013;13:140-9.

24. Nioche C, Orlhac F, Boughdad S, Reuzé S, Goya-Outi J, Robert C, Pellot-Barakat C, Soussan M, Frouin F, Buvat I. LIFEx: A Freeware for Radiomic Feature Calculation in Multimodality Imaging to Accelerate Advances in the
Characterization of Tumor Heterogeneity. Cancer Res 2018;78:4786-9.

25. Becker K, Mueller J, Schuhmacher C. Histomorphology and grading of regression in gastric cancer treated with neoadjuvant chemotherapy. Cancer 2003;98:1521-30.

26. Borrmann R, Henke F, Lubarsch O. Handbuch der Speziellen Patologischen Anatomie und Histologie. 1st edition. Berlin: Springer-Verlag, 1926.

27. Japanese Gastric Cancer Association. Japanese classification of gastric carcinoma: 3rd English edition". Gastric Cancer 2011;14:101-12.

28. De Manzoni G, Marrelli D, Baiocchi GL, Morgagni P, Saragoni L, Degiuli M, Donini A, Fumagalli U, Mazzei MA, Pacelli F, Tomezzoli A, Berselli M, Catalano F, Di Leo A, Framarini M, Giacopuzzi S, Graziosi L, Marchet A, Marini M, Milandri C, Mura G, Orsenigo E, Quagliuolo V, Rausei S, Ricci R, Rosa F, Roviello G, Sansonetti A, Sgroi G, Tiberio GA, Verlato G, Vindigni C, Rosati R, Roviello F. The Italian Research Group for Gastric Cancer (GIRCG) guidelines for gastric cancer staging and treatment: 2015. Gastric Cancer 2017;20:20-30.

29. Becker K, Reim D, Novotny A, Zum Büschenfelde CM, Engel J, Friess H, Höfler H, Langer R. Proposal for a multifactorial prognostic score that accurately classifies 3 groups of gastric carcinoma patients with different outcomes after neoadjuvant chemotherapy and surgery. Ann Surg 2012;256:1002-7.

30. Amin MB, Edge S, Greene F, Byrd DR, Brookland RK, Washington MK, Gershenwald JE, Compton CC, Hess KR, Sullivan DC, Jessup JM, Brierley JD, Gaspar LE, Schilsky RL, Balch CM, Winchester DP, Asare EA, Madera M, Gress DM, Meyer LR. editors. AJCC Cancer Staging Manual. 8th edition. New York, NY: Springer, 2017.

31. van der Schaaf A, Xu CJ, Van Luijk P, Van't Veld AA, Langendijk JA, Schilstra C. Multivariate modeling of complications with data driven variable selection: guarding against overfitting and effects of data set size. Radiother Oncol 2012;105:115-21.

32. Nardone V, Reginelli A, Scala F, Carbone SF, Mazzei MA, Sebaste L, Carfagno T, Battaglia G, Pastina P, Correale P, Tini P, Pellino G, Cappabianca S, Pirtoli L. Magnetic-Resonance-Imaging Texture Analysis Predicts Early Progression in Rectal Cancer Patients Undergoing Neoadjuvant Chemoradiation. Gastroenterol Res Pract 2019;2019:8505798.

33. Lauren P. The two histological main types of gastric carcinoma: diffuse and so-called intestinal-type carcinoma. 
An attempt at a histo-clinical classification. Acta Pathol Microbiol Scand 1965;64:31-49.

34. Song Z, Wu Y, Yang J, Yang D, Fang X. Progress in the treatment of advanced gastric cancer. Tumour Biol 2017;39:1010428317714626.

35. Mazzei MA, Bagnacci G, Gentili F, Nigri A, Pelini V, Vindigni C, Mazzei FG, Baiocchi GL, Pittiani F, Morgagni P, Petrella E, Mura G, Verdelli B, Bencivenga M, Giacopuzzi S, Marrelli D, Roviello F, Volterrani L. Gastric Cancer Maximum Tumour Diameter Reduction Rate at CT Examination as a Radiological Index for Predicting Histopathological Regression after Neoadjuvant Treatment: A Multicentre GIRCG Study. Gastroenterol Res Pract 2018;2018:1794524.

36. Park SR, Lee JS, Kim CG, Kim HK, Kook MC, Kim YW, Ryu KW, Lee JH, Bae JM, Choi IJ. Endoscopic ultrasound and computed tomography in restaging and predicting prognosis after neoadjuvant chemotherapy in patients with locally advanced gastric cancer. Cancer 2008;112:2368-76.

37. Tang L, Li ZY, Li ZW, Zhang XP, Li YL, Li XT, Wang ZL, Ji JF, Sun YS. Evaluating the response of gastric carcinomas to neoadjuvant chemotherapy using iodine concentration on spectral CT: a comparison with pathological regression. Clin Radiol 2015;70:1198-204.

38. Sun Z, Cheng X, Ge Y, Shao L, Xuan Y, Yan G. An application study of low-dose computed tomography perfusion imaging for evaluation of the efficacy of neoadjuvant chemotherapy for advanced gastric adenocarcinoma. Gastric Cancer 2018;21:413-20.

39. Kruk-Bachonko J, Krupski W, Czechowski M, KurysDenis E, Mądro P, Sierocińska-Sawa J, Dąbrowski A, Wallner G, Skoczylas T. Perfusion CT - A novel quantitative and qualitative imaging biomarker in gastric cancer. Eur J Radiol 2017;95:399-408.

40. Grassi R, Pinto A, Mannelli L, Marin D, Mazzei MA. New Imaging in Gastrointestinal Tract. Gastroenterol Res Pract 2016;2016:5785871.

41. Mazzei MA, Preda L, Cianfoni A, Volterrani L. CT perfusion: technical developments and current and future applications. Biomed Res Int 2015;2015:397521.

42. Mazzei FG, Volterrani L, Guerrini S, Cioffi Squitieri N, Sani E, Bettini G, Pozzessere C, Mazzei MA. Reduced time CT perfusion acquisitions are sufficient to measure the permeability surface area product with a deconvolution method. Biomed Res Int 2014;2014:573268.

43. Mazzei MA, Squitieri NC, Sani E, Guerrini S, Imbriaco G, Di Lucia D, Guasti A, Mazzei FG, Volterrani L. Differences in perfusion CT parameter values with commercial software upgrades: a preliminary report about algorithm consistency and stability. Acta Radiol 2013;54:805-11.

44. Messina C, Bignone R, Bruno A, Bruno A, Bruno F, Calandri M, Caruso D, Coppolino P, Robertis R, Gentili F, Grazzini I, Natella R, Scalise P, Barile A, Grassi R, Albano D. Diffusion-Weighted Imaging in Oncology: An Update. Cancers (Basel) 2020;12:1493.

45. Mazzei MA, Cioffi Squitieri N, Vindigni C, Guerrini S, Gentili F, Sadotti G, Mercuri P, Righi L, Lucii G, Mazzei FG, Marrelli D, Volterrani L. Gastrointestinal stromal tumors (GIST): a proposal of a "CT-based predictive model of Miettinen index" in predicting the risk of malignancy. Abdom Radiol (NY) 2020;45:2989-96.

46. Volterrani L, Gentili F, Fausto A, Pelini V, Megha T, Sardanelli F, Mazzei MA. Dual-Energy CT for Locoregional Staging of Breast Cancer: Preliminary Results. AJR Am J Roentgenol 2020;214:707-14.

47. Fave X, Zhang L, Yang J, Mackin D, Balter P, Gomez D, Followill D, Jones AK, Stingo F, Liao Z, Mohan R, Court L. Delta-radiomics features for the prediction of patient outcomes in non-small cell lung cancer. Sci Rep 2017;7:588.

48. Chen W, Giger ML, Li H, Bick U, Newstead GM. Volumetric texture analysis of breast lesions on contrastenhanced magnetic resonance images. Magn Reson Med 2007;58:562-71.

49. Haider MA, Vosough A, Khalvati F, Kiss A, Ganeshan B, Bjarnason GA. CT texture analysis: a potential tool for prediction of survival in patients with metastatic clear cell carcinoma treated with sunitinib. Cancer Imaging 2017;17:4.

50. Ng F, Ganeshan B, Kozarski R, Miles KA, Goh V. Assessment of Primary Colorectal Cancer Heterogeneity by Using Whole-Tumor Texture Analysis: Contrastenhanced CT Texture as a Biomarker of 5-year Survival. Radiology 2013;266:177-84.

51. Nardone V, Reginelli A, Guida C, Belfiore MP, Biondi M, Mormile M, Banci Buonamici F, Di Giorgio E, Spadafora M, Tini P, Grassi R, Pirtoli L, Correale P, Cappabianca S, Grassi R. Delta-radiomics increases multicentre reproducibility: a phantom study. Med Oncol 2020;37:38.

52. Nardone V, Tini P, Nioche C, Biondi M, Sebaste L, Mazzei MA, Banci Buonamici F, Pirtoli L. Texture analysis of parotid gland as a predictive factor of radiation induced xerostomia: A subset analysis. Radiother Oncol 2017;122:321.

53. Nardone V, Tini P, Carbone SF, Grassi A, Biondi M, 
Sebaste L, Carfagno T, Vanzi E, De Otto G, Battaglia G, Rubino G, Pastina P, Belmonte G, Mazzoni LN, Banci Buonamici F, Mazzei MA, Pirtoli L. Bone texture analysis using CT-simulation scans to individuate risk parameters for radiation-induced insufficiency fractures. Osteoporos Int 2017;28:1915-23.

54. Nardone V, Tini P, Nioche C, Mazzei MA, Carfagno T, Battaglia G, Pastina P, Grassi R, Sebaste L, Pirtoli $\mathrm{L}$. Texture analysis as a predictor of radiation-induced xerostomia in head and neck patients undergoing IMRT. Radiol Med 2018;123:415-23.

55. Nardone V, Tini P, Croci S, Carbone SF, Sebaste L, Carfagno T, Battaglia G, Pastina P, Rubino G, Mazzei MA, Pirtoli L. 3D bone texture analysis as a potential predictor of radiation-induced insufficiency fractures. Quant Imaging Med Surg 2018;8:14-24.

56. Yoon SH, Kim YH, Lee YJ, Park J, Kim JW, Lee HS, Kim B. Tumor Heterogeneity in Human Epidermal Growth Factor Receptor 2 (HER2)-Positive Advanced Gastric Cancer Assessed by CT Texture Analysis: Association with Survival after Trastuzumab Treatment. PLoS One 2016;11:e0161278.

57. Giganti F, Marra P, Ambrosi A, Salerno A, Antunes S, Chiari D, Orsenigo E, Esposito A, Mazza E, Albarello L, Nicoletti R, Staudacher C, Del Maschio A, De Cobelli F.

Cite this article as: Mazzei MA, Di Giacomo L, Bagnacci G, Nardone V, Gentili F, Lucii G, Tini P, Marrelli D, Morgagni P, Mura G, Baiocchi GL, Pittiani F, Volterrani L, Roviello F. Delta-radiomics and response to neoadjuvant treatment in locally advanced gastric cancer-a multicenter study of GIRCG (Italian Research Group for Gastric Cancer). Quant Imaging Med Surg 2021;11(6):2376-2387. doi: 10.21037/qims-20-683
Pre-treatment MDCT-based texture analysis for therapy response prediction in gastric cancer: Comparison with tumour regression grade at final histology. Eur J Radiol 2017;90:129-37.

58. Liu S, Liu S, Ji C, Zheng H, Pan X, Zhang Y, Guan W, Chen L, Guan Y, Li W, He J, Ge Y, Zhou Z. Application of CT texture analysis in predicting histopathological characteristics of gastric cancers. Eur Radiol 2017;27:4951-9.

59. Ba-Ssalamah A, Muin D, Schernthaner R, KulinnaCosentini C, Bastati N, Stift J, Gore R, Mayerhoefer ME. Texture-based classification of different gastric tumors at contrast-enhanced CT. Eur J Radiol 2013;82:e537-43.

60. Mazzei MA, Nardone V, Di Giacomo L, Bagnacci G, Gentili F, Tini P, Marrelli D, Volterrani L. The role of delta radiomics in gastric cancer. Quant Imaging Med Surg 2018;8:719-21.

61. Rao SX, Lambregts DM, Schnerr RS, Beckers RC, Maas M, Albarello F, Riedl RG, Dejong CH, Martens MH, Heijnen LA, Backes WH, Beets GL, Zeng MS, BeetsTan RG. CT texture analysis in colorectal liver metastases: A better way than size and volume measurements to assess response to chemotherapy? United European Gastroenterol J 2016;4:257-63. 